\title{
COVID-19 and Face Mask Use: A St. Kitts Case Study
}

\author{
Yulia Kungurova ${ }^{1}$, Ritha Mera ${ }^{2}$, Evelyn Brewster ${ }^{1}$, Khalil $\mathrm{Ali}^{2}$, Adegbenro O.J. Fakoya $^{3 *}$ \\ ${ }^{1}$ Medical students, University of Medicine and Health Science, Basseterre, St. Kitts and Nevis; ${ }^{2}$ Medical students, Windsor \\ University School of Medicine, Cayon, St. Kitts and Nevis; ${ }^{3}$ Associate Professor, Department of Anatomy, University of Medicine \\ and Health Sciences, Basseterre, St. Kitts and Nevis
}

\section{Abstract}

Edited by: Mirko Spirosk Citation: Kungurova Y, Mera R, Brewster E, Ali K, Fakoya AOJ. COVID-19 and Face Mask Use: A St. Kitts Case Study. Open Access Maced J Med Sci. 2020 Oct 26 8(T1):346-352. https://doi.org/10.3889/oamjms.2020.5289 Keywords: Personal protective equipment; COVID-19, N95 mask; Surgical mask; Handmade mask; Adherence, Compliance; Caribbean *Correspondence: Adegbenth Omoluyi John Fakoya, Nevis. E-mail: afakoya@umhs-sk net, Fax: 869.466.1682, Phone: +1869-763-1068 Received: 20-Jul-2020 Revised: 12-Oct-2020 Accepted: 16-Oct-2020
Copyright: $\odot 2020$ Yulia Kungurova, Ritha Mera, Evelyn Brewster, Khalil Ali, Adegbenro O.J. Fakoya Funding: Publication of this article was financially Republic of Macedonia Republic of Macedonia
Competing Interest: The authors have declared that no
competing interest exists Republic of Macedonia
Competing Interest: The authors have declared that no
competing interest exists Open Access: This is an open-access article distribute
under the terms of the Creative Commons AtributionNonCommercial 4.0 International License (CC BY-NC 4.0)

\section{Introduction}

Masks have been flying off store shelves virtually and physically leading to worldwide shortages, leaving front line workers and the general population vulnerable and unprotected because of the everchanging landscape of the COVID-19 pandemic. The first reports of the virus were in December of 2019 , but it was not until late January that person to person transmission was reported [1]. Unfortunately, the Center for Disease Control (C.D.C.), the World Health Organization (WHO)/Pan American Health Organization (PAHO), and the St. Christopher and Nevis government have differing opinions on the use of masks amid this pandemic. As of April 3, 2020, the C.D.C. released a recommendation for the full use of face masks, specifically recommending them in areas with significant community-based transmission [2]. Due to the shortage of surgical and N95 masks, the C.D.C. has been firmly steering the general population toward handmade cloth masks. This C.D.C. recommendation reverses their previous advice that only healthcare workers or those dealing directly with the infection should be wearing masks [3].
Similarly, St. Christopher and Nevis, through their Ministry of Health, issued protocols in their daily COVID briefing on April 3, 2020, encouraging citizens to wear masks when in public, in contrast to their previous statements that restricted the use of masks to medical professionals [4]. Universal community masking was integrated into the Statutory Rules and Orders for the Federation shortly thereafter, explicitly stating: "A person shall wear a face mask, covering their nose and mouth, when in a public place once a period of emergency is declared concerning COVID19" [5]. Conversely, the WHO/PAHO has not veered from their original advice and does not endorse maskwearing by the general population. Instead, they firmly suggest that masks, especially N95 and surgical masks, be for medical personnel only, which would, therefore, curve worldwide shortages. The WHO/PAHO believes that masks may provide a false sense of security for community members because it may lead to the neglect of personal hand hygiene practices, reduce physical distancing and even lead to excessive touching of the face and eyes [6]. They further suggested that there is limited evidence that wearing a medical mask by healthy individuals while interacting with sick contacts or those in large gatherings is significantly beneficial in 
prevention; as well as the lack of evidence supporting universal community masking and the reduction in respiratory infection such as COVID-19 [6].

As the C.D.C. and WHO/PAHO are attempting to flatten the curve and reduce community-based transmissions, the twin-island Federation of St. Christopher and Nevis has equally made great strides in the war against COVID-19 allowing for a perfect opportunity to create mask guidelines for this pandemic and future one.

\section{Background into the Widespread mask use in St. Kitts}

The use of masks during flu season and other pandemics is nothing new. It has always been recommended that individuals who are sick or show potential symptoms should wear proper personal protective equipment (P.P.E.) to protect the general public. The concern with the COVID-19 is that it has become increasingly understood that many people can carry the virus and spread it while being asymptomatic. In Monterey County, California, it was found that $29 \%$ of their current COVID-19 patients acquired the virus from being in the general public, and not due to direct contact with a positive patient [7]. It has additionally been shown that with each individual positive for COVID-19, there has been statistical spread to up to four other individuals during this pandemic [8].

Mask use in the public can be correlated with the effectiveness of masks in hospital settings as it has been shown to reduce the spread of infection in aerosolbased viruses dramatically. A 2014 Saudi Arabian study investigated medical staff in contact with Middle East respiratory syndrome coronavirus, another type of coronavirus. It showed that the group that used N95 masks had a $56 \%$ decrease in transmission compared to those that did not [9]. The use of surgical masks in a surgical setting has recently come under scrutiny after a 2016 Cochrane review concluded that wearing a mask during surgery has no effect on the number of wound infections [10]. Another literature review of surgical mask use highlighted the possibility of "venting," where air leaks at the interface between the mask and skin through the path of least resistance, as well as facilitation of contaminant movement through capillary action with moisture accumulation [11]. Finally, a review of the evidence for surgical mask use showed studies to be out of date, and largely of poor methodology - but concludes that absence of evidence of effectiveness is not to be equated with evidence of ineffectiveness; and without evidence that masks cause harm, acknowledge that proponents of mask use in the surgical setting prefer to stay on the side of caution and continue the practice of mask-use [12].
There are three ways of transmission for respiratory viruses - airborne (with droplet particles 5-10 um), droplet (<5 um), and direct contact (of fomites directly touched by infected persons) [13]. According to the WHO guidelines, COVID-19 is transmitted in the community by droplets and fomites that can carry the virus from the hands to the mouth or nose and is only airborne when intensive intervention measures such as endotracheal intubation, bronchoscopy, and positive pressure intubation which indicates a higher risk environment for healthcare workers and necessitates the use of N95 masks [13]. COVID-containing droplets have been shown to remain suspended in air for up to $3 \mathrm{~h}$ with the infectious titer reducing from $10^{3.5}$ to $10^{2.7} \mathrm{TCID}_{50}$ per liter of air or land on surfaces and remain there for up to $72 \mathrm{~h}$ on steel and plastic, with infectious titers decreasing from $10^{3.7}$ to $10^{0.6}$ $\mathrm{TCID}_{50}$ in $48 \mathrm{~h}$ on steel and in $72 \mathrm{~h}$ on plastic [14]. A 2009 study of influenza patients showed $7 / 9$ collected cough droplets had detectable virus compared to none of those who coughed through an N-95 mask - however, it is not a study of transmission directly [15]. Further evidence for the possibility of aerosol transmission comes from the severe acute respiratory syndrome (SARS) outbreak in 2003, where it was found that recycled air in a housing building in China spread the SARS virus by transporting aerosols to other units several floors higher [16]. Due to these findings, more and more governments around the world have started implementing policies requiring general public use of masks.

Education of the general public, government officials, and their media on the proper use of P.P.E. and viral transmission in China and Taiwan has actively increased compliance [17]. The aim is to prevent the spread of COVID-19 from infected individuals through the use of masks, as well as reducing the risk of uninfected individuals becoming infected through improper mask use. The most significant task of educating the general public on mask use is to give them guidelines on the effective use of masks, mask disposal, and the mode of contracting COVID-19. Of importance is the mask disposal, as the virus can be resuspended as an aerosol [18]. While individuals may be able to avoid catching the virus in the general public, there remains a risk of bringing it home and contracting it from improper techniques of mask removal and disposal.

In this study, we aim to look at the types of face masks worn in St. Kitts, and the errors associated with the use of these types of masks. We also aim to relate our findings to the psychological relevance of the use of face mask, possible preemptive fear of the virus, and whether the threat is being taken seriously by the citizens of St. Kitts.

\section{St. Kitts demographics}

According to C.D.C., several groups are at a higher risk for severe disease presentation for 
COVID-19: Those over 65 years, residents of nursing homes, persons of all ages with poorly controlled lung disease, serious heart conditions, immunocompromised, severe obesity, diabetes, chronic kidney, and liver disease [19]. In the epidemiological review of the 2009 H1N1 outbreak in the Caribbean, it was shown that a significant proportion of hospitalized persons $(24 \%)$ had underlying medical conditions, compared to $1 \%$ who was previously healthy. With a case mortality rate of $1.8 \%$, with the highest among the 65-69 and 60-64 groups (33\% and $13 \%$, respectively), and more than half had underlying health conditions (diabetes, asthma, and congestive heart failure) [20].

Limited data on non-communicable chronic disease in St. Kitts exists. Still, the 2008 STEPs survey shows a high prevalence of the non-communicable disease in the population $-45 \%$ are obese, $26.5 \%$ have Stage I hypertension (vs. $19.5 \%$ diagnosed), $7.6 \%$ have been diagnosed with diabetes, and $8.8 \%$ have been told they have high cholesterol [21]. With a significant proportion of the population at a higher level of risk of developing complications, the local transmission policies such as public mask use and mandatory social distancing measures seem prudent.

\section{Caribbean}

\section{Testing for respiratory viruses in the}

Before the H1N1 epidemic spread to the Caribbean in May 2009, testing for influenza and other respiratory viruses were very limited. The only published report of respiratory virus trends in the Caribbean identified difficulty in analyzing seasonal trends before November 2010 due to the lack of data; and expressed concern that $78 \%$ of samples submitted to the Caribbean Epidemiology Center came from only 3 of the 26 Caribbean countries [20]. The recommendation was to drastically increase testing to establish reliable patterns. However, no known published data exist till date. Hence, there are no publicly available statistics on whether St. Kitts has had a higher incidence of influenza-negative pneumonia this winter before the implementation of testing mid-March 2020, as this trend has been suggested in other sources previously [22].

A further complication with COVID-19 is that asymptomatic carriers contribute to rapid viral spread - a California study with antibody testing of 3300 individuals suggests that the actual number of those who have been exposed to COVID-19 is $50-80$ times greater than the number of confirmed positive cases [23]. The premise is that masks are worn by the general public to prevent droplet transmission when an infected person sneezes or coughs, as well as droplets released when speaking by asymptomatic carriers. Hence, in the absence of adequate universal testing, all should be presumed carriers until proven otherwise.

\section{Methodology for this Case Study}

Asides limiting viral transmissions, masks have also been claimed to increase the level of self-awareness, that is, to reduce face touching and practice social distancing. WHO has stated that incorrect use of masks can increase transmission instead of curbing it [24].

The method of observation was structured as follows: in downtown Basseterre, St. Kitts from the $21^{\text {st }}$ to April 30, 2020, we surveyed three environments street, public transportation, and grocery store line. We observed each person for $5 \mathrm{~min}$, and for every person, we noted the type of mask worn, as well as whether errors in wearing them were made - not covering the nose, not covering the mouth, and touching the face.

\section{Results}

Of the 468 persons observed altogether, 74 had N95 masks (16.01\%), 156 had surgical masks (33.3\%), 102 had handmade masks (21.79\%), 67 had a bandana (14.32\%), and 69 had no mask $(14.74 \%)$ (Table 1).

Table 1: \% errors by mask type

\begin{tabular}{lllllll}
\hline Condition & N95 (\%) & $\begin{array}{l}\text { Surgical } \\
\text { mask (\%) }\end{array}$ & $\begin{array}{l}\text { Handmade } \\
\text { mask (\%) }\end{array}$ & $\begin{array}{l}\text { Bandana/ } \\
\text { scarf (\%) }\end{array}$ & $\begin{array}{l}\text { No mask } \\
(\%)\end{array}$ & Total \\
\hline $\begin{array}{l}\text { Not covering nose/ } \\
\text { mouth by mask type }\end{array}$ & 39.19 & 41.67 & 33.33 & 41.79 & 100 & 48.08 \\
$\begin{array}{l}\text { Touching their face } \\
\text { by mask type }\end{array}$ & 18.92 & 15.38 & 25.49 & 13.43 & 5.8 & 16.45 \\
\hline
\end{tabular}

These data suggests that at the moment of observation, $48.08 \%$ of persons were not covering their nose/mouth correctly and $16.45 \%$ were touching their face with their hands. Handmade mask users were more likely to have the mask properly covering their mouth and nose - possibly because they were more comfortable to wear. The same group, however, appeared to touch their face more often while wearing the mask. Wearing any face-covering seemed to lead to more face touching than no covering at $18.25 \%$ versus $5.8 \%$.

Comparing medical masks (N95 and surgical) to nonmedical masks (bandanas and handmade) suggested that nonmedical masks had a higher face touching probability at $20.71 \%$ versus $16.45 \%$ for medical. Table 2 indicates that of all errors observed, leaving the mouth/nose uncovered while wearing a surgical mask comprised the highest portion of total mistakes observed at $12.08 \%$. It also suggests that wearing any mask led to more face touching than not wearing a mask at all.

Table 2: \% errors of total errors

\begin{tabular}{llllll}
\hline Setting & $\begin{array}{l}\text { N95 } \\
(\%)\end{array}$ & $\begin{array}{l}\text { Surgical } \\
\text { mask (\%) }\end{array}$ & $\begin{array}{l}\text { Handmade } \\
\text { mask (\%) }\end{array}$ & $\begin{array}{l}\text { Bandana/ } \\
\text { scarf (\%) }\end{array}$ & $\begin{array}{l}\text { No mask } \\
(\%)\end{array}$ \\
\hline Touching face of total errors & 2.6 & 4.46 & 4.83 & 1.67 & 0.74 \\
$\begin{array}{l}\text { Uncovered nose/mouth of the } \\
\text { total \# errors? }\end{array}$ & 5.39 & 12.08 & 6.32 & 5.2 & 15.75 \\
\hline
\end{tabular}




\section{Discussion}

While policy implementations such as public mask-wearing are perceived to be beneficial for reducing viral spread, data suggest that there is also a positive psychological impact. In a recent study, it was found that early implementation of preventive measures, such as mask use, lowered levels of depression, anxiety, stress, and many other psychological symptoms that can arise from a pandemic [8]. It is thought that this is because early planning and implementation of protective measures by the government gave reassurance and control to the general public. There is evidence that this belief is applicable in the Caribbean as a Jamaican news agency conducted a poll on mask use and found $48 \%$ of respondents believe a nation-wide mandate is only effective in curtailing COVID-19 spread if everyone uses them correctly, compared to $12 \%$ who do not believe masks are effective at all, and $8 \%$ that believe quarantine measures are sufficient [25]. Our study also corroborated the positive psychology behind mask use as about $85 \%$ of the population observed had a form of face covering.

An important distinction should be made between members of the public that use medical-grade masks and homemade replacements. For one, public perception of the validity of threat has implications on the protective choices being made by individuals. A study of people's attitudes during the SARS epidemic in 2004 showed that 21/103 people concerned about SARS bought a mask ahead of time, while 10/146 not concerned bought one in Toronto which was the North American Epicenter, while in the USA 4/121 concerned and $3 / 387$ not concerned bought one out of those surveyed [26]. It is plausible to suggest that individuals who were concerned about COVID had procured a medical-grade mask when they were available on the market. Our study revealed $16.01 \%$ and $33.3 \%$ of our observed population had N95 and surgical masks, respectively, accounting for about $50 \%$ with a medicalgrade mask. This finding suggests a likely correlation with an increased level of preemptive fear locally. Although local Caribbean analyses of attitudes are not available, evidence can be found elsewhere [27].

While there are claims in the American media that blacks have been disproportionately affected by COVID-19 due to them not taking the threat seriously and neglecting the advice of public health officials, a national survey by Pew Research Center between March 10 and 16 showed that $46 \%$ black respondents viewed the COVID-19 as a major threat to their health, compared to $21 \%$ of white respondents; and $23 \%$ of white respondents did not believe this to be a threat at all compared to $21 \%$ black respondents [27]. Our findings suggest that the residents of St. Kitts, who are predominantly black, are taking this threat seriously as $85 \%$ of the observed population had a face covering as advised by the Government of St. Kitts and Nevis.
According to C.D.C. guidelines, a face mask should be taken off by the ear bands and avoiding touching the front of the mask, which has a high likelihood of being contaminated. One study done on adherence to proper techniques of P.P.E. removal of healthcare practitioners studied 162 instances in the care for 52 patients with respiratory symptoms, of whom 30 were in droplet and contact isolation, 21 in droplet, and 1 in contact [28]. It was found that of these interactions, $26 \%$ of healthcare workers removed the mask from the front and not by the loops, and $49 \%$ touched the potentially contaminated front with their bare hands during disgowning. Overall, accounting for the gowns, gloves, face shields, and mask procedures and sequence of doffing, the study showed a $90 \%$ error rate [28]. While healthcare workers in this study had many more steps of P.P.E. donning/removal than the average mask wearer in public, this study suggests that even individuals who have been trained in proper P.P.E. procedures make a significant number of errors. Although our study only considered the face mask, we observed that $16.45 \%$ of those who had a face covering touched the front of their mask and this percentage might have been higher had we observed the sample population for a longer period of time.

There has been limited data on adherence to mask use in the general population. A randomized control study of limitation of the familial spread of influenza had family members of confirmed cases wear surgical masks any time the index case or other symptomatic person was in the same room. Information was also provided for proper use of masks through a phone-call explanation and followed up with an in-home visit by study personnel to demonstrate the correct use of the intervention. Adherence to mask-wearing was around $50 \%$ for days 3-6 and then decreased afterward [29]. Our study revealed a non-adherence to proper use of the P.P.E. as $48.08 \%$ did not cover their nose and mouth correctly. The main issues cited by participants were heat/humidity (53\% children, 35\% adults) and pain/discomfort [29]. The concerns cited by these participants were reflected in our study as our data revealed that the use of medical-grade masks showed a greater percentage of non-adherence compared to the handmade mask, which seemed more comfortable with less heat and humidity. However, nonmedical masks had a higher face touching probability at $20.71 \%$ versus $16.45 \%$ for medical.

The public views the surgical mask as a method of prevention of the virus. The German sociologist Ulrich Beck formulated that "risk occurs not only in the form of threat and possible loss but also in society's organized management and response to these risks, which create a forwarding of present risk into the future." Thus, a mask becomes the cosmetic symbol for eliminating risk, while effective measures such as social distancing, proper mask wear, and hand hygiene are downplayed [30]. Our study showed that 
wearing any face-covering appeared to lead to more face touching than no covering at $18.25 \%$ versus $5.8 \%$. The question then is; could non-adherence to proper face mask use be more of a risk to contracting the virus than no covering at all, while ensuring social distancing as the pivot?

\section{Recommendation}

After the 1996 plague outbreak in India, Dr. Alladi Mohan expressed concerns toward proper mask use and its efficacy [25]. He recommended proper education for masks to cover nose and mouth, investigating materials to decrease pore size to under $5 \mathrm{um}$, and changing masks every 30-40 min in noninfectious areas, and more frequently in high-exposure areas [31].

Today, in a different pandemic, we are recommending much of the same - public health education in conjunction with prudent national policies. There is much to be learned from patient adherence literature, which cites $40 \%$ of patients to not comply with physician recommendations, and which recommends participatory decision making and reciprocal information sharing to increase compliance [32]. In the future, more efforts should be expended at schools and workplaces to educate on basic disease processes. In addition to implementing regulation, there is a need to use public messaging that considers barriers to change. One way is to highlight the gap between thoughts and action, as studies have shown that cognitive dissonance is a powerful impetus for changing behavior [33]. For example, as many persons seen not wearing masks were the young individuals, public health officials should highlight that masks are used for protecting others in case one is an asymptomatic carrier. The use of questions instead of direct messaging shifts the role of the listener from mentally organizing counterarguments to formulating an opinion which requires weighing of personal beliefs and feelings and increases buy-in into the call of action [34].

Finally, much of the messaging associated with the pandemic has asked the public to make drastic broad changes such as banning all public gatherings and cutting off all nonessential social interactions. However, studies show that having large scale demand is more likely to be rejected than using a "foot-in-thedoor" technique and gradually increasing the demand in manageable portions [35].

Looking inward, the government and the Ministry of Health of St. Kitts and Nevis should be given a lot of credit for their conscientiousness. The government instituted a full lockdown and a week after the first two cases on March 24, 2020, a complete lockdown on March 31, 2020, and politically ensured mandatory face mask use and other preventive measures [36]. Despite the errors observed in the face mask use, the result of this intervention is undeniable as the number of cases has stayed stable at 15 since April 20, 2020 [36]. At the time of submission of this manuscript, all the infected patients have recovered with no new cases. The government of St. Kitts and Nevis has proven that these measures have been effective, and if had been implemented earlier in some regions, might have helped to reduce the spread and save lives.

Overall, the recommendation for the future is that public education campaigns on potential pandemic management, viral transmission, and risk reduction should begin in times of stability so that the population is prepared to accept the necessary measures when the time comes.

\section{Limitation}

The observation was 5 min per person, and there was no basis for the choice of observational time. Hence, there is every possibility that the statistics might be altered by increased time. However, as a justification, our literature search did not show any study of this nature that we could have used as a possible basis for comparison of observational time.

\section{Conclusion}

In this COVID-19 pandemic, the Caribbean, specifically StChristopher and Nevis, must examine public adherence to universal community masking holistically; by not only combining the positive psychological effects but also the correct technique of mask usage.

Public health education must be the catalyst that ushers innovative and comprehensive legislation and policy into the Federation. Education encompassing hygiene, social distancing, and adequate use of respiratory protectors can potentially eliminate community-acquired transmission and aid to flatten the disease curve drastically.

\section{References}

1. World Health Organization. Timeline-COVID-19. Geneva: World Health Organization; 2020. Available from: https://www.who. int/news-room/detail/08-04-2020-who-timeline---covid-19. [Last accessed on 2020 Apr 27].

2. Coronavirus Disease 2019 (COVID-19). Centers for Disease Control and Prevention. Available from: https://www.cdc.gov/ 
coronavirus/2019-ncov/prevent-getting-sick/cloth-face-cover. html. [Last accessed on 2020 Apr 27].

3. Coronavirus Disease 2019 (COVID-19). Centers for Disease Control and Prevention. Available from: https://www.cdc.gov/ coronavirus/2019-ncov/faq.html\#anchor_1584386949645. [Last accessed on 2020 Apr 27].

4. National Broadcasting of St. Kitts-Nevis. The National Emergency Operation Center (NEOC) COVID-19 Daily Briefing; 2020. Available from: https://www.youtube.com/ watch? $=6 \mathrm{cTZyu} 90 \mathrm{Ns}$. [Last accessed on $2020 \mathrm{Apr} 27$ ].

5. Government of Saint Christopher and Nevis. Statutory Rules and Orders: Emergency Powers (COVID-19) (No.5) Regulations. Basseterre: Extra-Ordinary Gazette; 2020. p. 6.

6. World Health Organization. Advice on the Use of Masks in the Contact of COVID-19: Interim Guidance. Geneva: World Health Organization; 2020. p. 1-2.

7. County of Monterey. 2019 Novel Coronavirus (COVID19)-local Data. Available from: https://www.co.monterey. ca.us/government/departments-a-h/health/diseases/2019novel-coronavirus-2019-ncov/2019-novel-coronavirus2019-ncov-local-data?fbclid=IWAROWOdySICT86VmIvAtR T5r-XUdMRUZX-Kwlo1OZJMJ7IWeJINe6zMOB8S0. [Last accessed on 2020 Apr 21].

8. Wang C, Pan R, Wan X, Tan Y, Xu L, Ho CS, et al. Immediate psychological responses and associated factors during the initial stage of the 2019 coronavirus disease (COVID-19) epidemic among the general population in China. Int J Environ Res Public Health. 2020;17(5):1729. https://doi.org/10.3390/ ijerph17051729

PMid:32155789

9. Alraddadi BM, Al-Salmi HS, Jacobs-Slifka K, Slayton RB, Estivariz CF, Geller Al, et al. Risk factors for middle east respiratory syndrome coronavirus infection among healthcare personnel. Emerg Infect Dis. 2016;22(11):1915-20. https://doi. org/10.3201/eid2211.160920

PMid:27767011

10. Lipp A, Edwards P. Disposable surgical face masks for preventing surgical wound infection in clean surgery. Cochrane Database Syst Rev. 2014;4(4):CD002929. https://doi. org/10.1002/14651858.cd002929.pub2

PMid:27115326

11. Schweizer RT. Mask wiggling as a potential cause of wound contamination. Lancet. 1976;2(7995):1129-30. https://doi. org/10.1016/s0140-6736(76)91101-6

PMid:62960

12. Da Zhou C, Sivathondan $P$, Handa A. Unmasking the surgeons: The evidence base behind the use of facemasks in surgery. J R Soc Med. 2015;108(6):223-8. https://doi. org/10.1177/0141076815583167

PMid:26085560

13. World Health Organization. Modes of Transmission of Virus Causing COVID-19: Implications for I.P.C. Precaution Recommendations. Geneva: World Health Organization; 2020. Available from: https://www.who.int/news-room/commentaries/ detail/modes-of-transmission-of-virus-causing-covid-19implications-for-ipc-precaution-recommendations. [Last accessed on 2020 Apr 21].

14. van Doremalen N, Bushmaker T, Morris DH, Holbrook MG, Gamble A, Williamson BN, et al. Aerosol and surface stability of SARS-CoV-2 as compared with SARS-CoV-1. N Engl J Med. 2020;382(16):1564-7. https://doi.org/10.1056/nejmc2004973 PMid:32182409

15. Larson EL, Liverman CT. Preventing Transmission of Pandemic Influenza and Other Viral Respiratory Diseases: Personal Protective Equipment for Healthcare Personnel: Update 2010. Institute of Medicine (U.S.) Committee on Personal Protective
Equipment for Healthcare Personnel to Prevent Transmission of Pandemic Influenza and Other Viral Respiratory Infections. Washington, DC, United States: National Academies Press; 2011.

16. Yu IT, Li Y, Wong TW, Tam W, Chan AT, Lee JH, et al. Evidence of airborne transmission of the severe acute respiratory syndrome virus. N Engl J Med. 2004;350(17):1731-9. https:// doi.org/10.1056/nejmoa032867

PMid:15102999

17. Zhong NS, Zeng GQ. Pandemic planning in China: Applying lessons from severe acute respiratory syndrome. Respirology. 2008;13(1):S33-5. https://doi. org/10.1111/j.1440-1843.2008.01255.x

PMid:18366527

18. Liu Y, Ning Z, Chen Y, Guo M, LiuY, Gali NK, et al. Aerodynamic characteristics and R.N.A. Concentration of SARS-CoV-2 aerosol in Wuhan hospitals during COVID-19 outbreak. BioRxiv. 2020.

19. CDC. People Who Are at Higher Risk for Severe Illness Coronavirus Disease 2019 Guidelines. Available from: https:// www.cdc.gov/coronavirus/2019-ncov/need-extra-precautions/ people-at-higher-risk.html. [Last accessed on $2020 \mathrm{Apr}$ 20].

20. Edwards L, Boisson E, Nathaniel-Girdharrie S, MorrisGlasgow V. Distribution of influenza and other acute respiratory viruses during the first year after the 2009-2010 influenza pandemic in the English and Dutch-speaking Caribbean countries. Influenza Other Respir Viruses. 2013;7(6):1062-9. https://doi.org/10.1111/irv.12126

PMid:23745666

21. Edwards P, Roberts W, Saheli B, Turner W, Fyfield J. St. Kitts and Nevis STEPwise Approach to Non-communicable Disease Risk Factor Survey. World Health Organization; 2007. Available from: https://www.who.int/ncds/surveillance/steps/2007 Report_StKitts.pdf. [Last accessed on 2020 Apr 12].

22. Parodi E, Aloisi S. Italian scientists investigate possible earlier emergence of coronavirus. BioXriv. 2020.

23. Bendavid E, Mulaney B, Sood N, Shah S, Ling L, BromleyDulfano R, et al. COVID-19 antibody seroprevalence in Santa Clara County, California. BioXRiv. 2020. https://doi. org/10.1101/2020.04.14.20062463

24. World Health Organization. Advice on the Use of Masks in the Community Setting in Influenza A (H1N1) Outbreaks. Geneva: World Health Organization; 2009. Available from: https://www.who.int/csr/resources/publications/ Adviceusemaskscommunityrevised.pdf. [Last accessed on 2020 Apr 22].

25. Rodgers K. COVID-19: All You Need to Know about Masks and How to Make Them; Loop Jamaica. Available from: https:// www.loopjamaica.com/content/covid-19-face-masks-nowencouragedwelp-escalated-quickly. [Last accessed on 2020 Apr 18].

26. Blendon RJ, Benson JM, DesRoches CM, Raleigh E, TaylorClark K. The public's response to severe acute respiratory syndrome in toronto and the United States. Clin Infect Dis. 2004;38(7):928-31. https://doi.org/10.1086/382355 PMid:15034821

27. Pew Research Center. U.S. Public Sees Multiple Threats from the Coronavirus and Concerns are Growing; 2020. Available from: https://www.people-press.org/2020/03/18/u-s-publicsees-multiple-threats-from-the-coronavirus-and-concerns-aregrowing. [Last accessed on 2020 Apr 18].

28. Phan LT, Maita D, Mortiz DC, Weber R, Fritzen-Pedicini C, Bleasdale SC, et al. Personal protective equipment doffing practices of healthcare workers. J Occup Environ Hyg. 2019;16(8):575-81. https://doi.org/10.1080/15459624.2019.162 8350 
PMid:31291152

29. Suess T, Remschmidt C, Schink SB, Schweiger B, Nitsche A, Schroeder K, et al. The role of facemasks and hand hygiene in the prevention of influenza transmission in households: Results from a cluster randomised trial; Berlin, Germany, 2009-2011. BMC Infect Dis. 2012;12:26. https://doi.org/10.1186/1471-2334-12-26 PMid:22280120

30. Neilson $\mathrm{S}$. The surgical mask is a bad fit for risk reduction. CMAJ. 2016;188(8):606-7. https://doi.org/10.1503/cmaj.151236 PMid:27067817

31. Mohan A, Misra A. Use of face masks during a plague epidemic. Postgrad Med J. 1996;72(844):127. https://doi.org/10.1136/ pgmj.72.844.127

PMid:8871470

32. Martin LR, Williams SL, Haskard KB, Dimatteo MR. The challenge of patient adherence. Ther Clin Risk Manag. 2005;1(3):189-99. PMid:18360559
33. Strangor C. Principles of Social Psychology. Victoria: Bccampus; 2014.

34. Berger J. How to Persuade People to Change Their Behavior. Harvard Business Review; 2020. Available from: https://www. hbr.org/2020/04/how-to-persuade-people-to-change-theirbehavior. [Last accessed on 2020 Apr 21].

35. Li WH, Ho KY, Lam KK, Wang MP, Cheung DY, Ho LL, et al. A study protocol for a randomised controlled trial evaluating the use of information communication technology (WhatsApp/ WeChat) to deliver brief motivational interviewing (i-BMI) in promoting smoking cessation among smokers with chronic diseases. BMC Public Health. 2019;19(1):1083. https://doi. org/10.1186/s12889-019-7417-6

PMid:31399047

36. COVID-19 Pandemic in Saint Kitts and Nevis; 2020. Available from: https://www.en.wikipedia.org/wiki/COVID-19_pandemic in_Saint_Kitts_and_Nevis. [Last accessed on 2020 May 09]. 